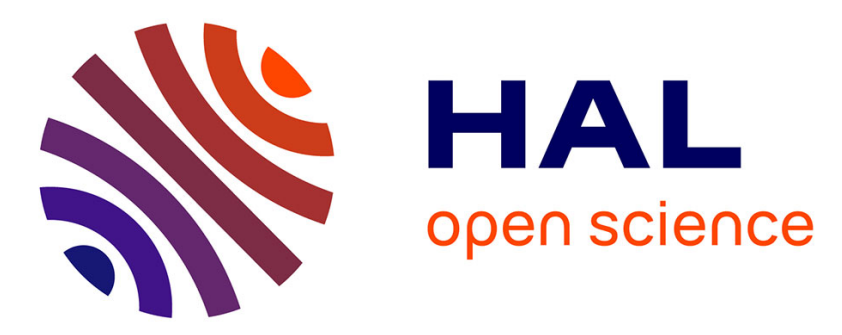

\title{
A new transient thermal fouling probe for cross flow tubular heat exchangers
}

\author{
L. Perez, Bruno Ladevie, P. Tochon, J.C. Batsale
}

\section{To cite this version:}

L. Perez, Bruno Ladevie, P. Tochon, J.C. Batsale. A new transient thermal fouling probe for cross flow tubular heat exchangers. International Journal of Heat and Mass Transfer, 2009, 52 (1-2), pp.407 - 414. 10.1016/j.ijheatmasstransfer.2008.05.029 . hal-01651393

\section{HAL Id: hal-01651393 https://imt-mines-albi.hal.science/hal-01651393}

Submitted on 7 Nov 2019

HAL is a multi-disciplinary open access archive for the deposit and dissemination of scientific research documents, whether they are published or not. The documents may come from teaching and research institutions in France or abroad, or from public or private research centers.
L'archive ouverte pluridisciplinaire HAL, est destinée au dépôt et à la diffusion de documents scientifiques de niveau recherche, publiés ou non, émanant des établissements d'enseignement et de recherche français ou étrangers, des laboratoires publics ou privés. 


\title{
A new transient thermal fouling probe for cross flow tubular heat exchangers
}

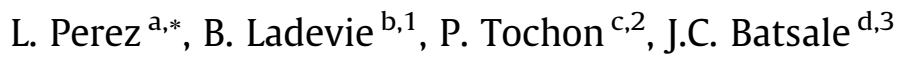 \\ a Laboratoire de Thermocinétique de Nantes, UMR CNRS 6607, Ecole Polytechnique de Nantes, Rue Christian Pauc, BP 50609, 44306 Nantes Cedex 3, France \\ ${ }^{\mathrm{b}}$ Laboratoire de Génie des Procédés des Solides Divisés, UMR CNRS 2392, Ecole des Mines d'Albi-Carmaux, Route de Teillet, Campus Jarlard, 81013 Albi Cedex 09, France \\ ${ }^{\mathrm{c}}$ GRETh, CEA, 17 Rue des Martyrs, 38054 Grenoble Cedex 09, France \\ ${ }^{\mathrm{d}}$ Laboratoire TREFLE, UMR CNRS 8508, Ecole ENSAM, Esplanade des Arts et Métiers, 33405 Talence Cedex, France
}

Keywords:

Particulate fouling

Tubular heat exchangers

Thermal sensor

Transient method

Weighted sum of transient data

Parameters estimation

\begin{abstract}
A B S T R A C T
The present probe is developed in order to accurately estimate in situ not only the convective exchange coefficient but also the fouling thickness of heat exchangers from a reliable transient state estimation method.The originality of the estimation method consists in considering a global response time of the system in fouling conditions to be compared to clean conditions. The sensitivity function is then built from the experimental signal without precise knowledge about the model or the absolute thermophysical properties. The reliability of the method is demonstrated in theoretical cases and with calibrated experiments.
\end{abstract}

\section{Introduction}

Heat exchangers are used in numerous industrial processes. They can also be found as part of many systems in transportation and residential and tertiary applications. Most heat transfer operations involve the deposition of unwanted residues on exchange surfaces. In gaseous systems, the deposition of particulate matter constitutes the fouling. The effectiveness of heat exchangers can decrease because of this foulant deposition onto the heat transfer surface. Attempts have been made to model heat exchangers fouling. Pioneer work $[6,16]$, essentially an asymptotic curve-fitting exercise, tends to dominate the concepts and leaves much to empirism. Marner [9] reviewed several analytical and experimental studies relating developments in gas side fouling. Other models $[1-4,13,18,19]$ are based on deposition and removal mechanisms, but they still involve a strong empirical content.

Ever since the end of the 1970s, some gas-side fouling measuring devices have been envisaged [5,7,10-12,14,17]. All of them provide physical information on fouling. Nevertheless, they are still far from giving thermal information and taking into account the deposit phenomena involved.

\footnotetext{
* Corresponding author. Tel.: +33 240683 113; fax:+33 240683141.

E-mail addresses: laetitia.perez@univ-nantes.fr (L. Perez), bruno.ladevie@enstimac.fr (B. Ladevie), patrice.tochon@cea.fr (P. Tochon), jean-christophe.batsale@ bordeaux.ensam.fr (J.C. Batsale).

1 Tel.: +33 563493 223; fax: +33 563493243 .

2 Tel.: +33 438783 199; fax: +33 438785435 .

3 Tel.: +33 556845 425; fax: +33 556845401 .
}

Thus, although considerable work has been carried out through the years, it is clear that progresses remain to be made, more particularly to provide the basis for improved predictive methods. Currently, the various solutions, even if they are numerous and varied, are not completely satisfactory. However, they allowed to work out the main quality that a fouling probe has to present. In particular, it has to be cheap, easy to implement and it has to take into account the heat transfer and the deposit phenomena involved [20].

So, the here developed probe replaces directly a part (or the totality) of the tubular heat exchanger. This device can be described by a multilayered system where the transient temperature measurement is achieved simultaneously and at the same location as a thermal excitation. The associated data processing is developed in order to estimate the heat transfer coefficient and the particulate fouling thickness of tubular heat exchanger. Indeed, such parameters enable to determine heat exchangers fouling level.

The 3D transient heat transfer problem is modelled by an extension of the thermal quadrupole formalism. The study of the transfer function linking excitation to system temperature response allows the probe sizing and the theoretical sensitivity study establishment.

Since the probe must be used in harsh conditions, since the nominal values of the problem are not precisely known, the estimation method is directly realised from the experimental temperature responses. This method is sturdy and is based on an experimental sensitivity study. It does not require sophisticated physical considerations or complete forward model. So, two simplified transient forward models have been developed. 


\section{Nomenclature}

\section{Latin letters}

$A, B, C, D$ quadrupole coefficients

$C_{p} \quad$ constant pressure specific heat $\left(\mathrm{J} \mathrm{kg}^{-1} \mathrm{~K}^{-1}\right)$

$L \quad$ heater half length (m)

$M \quad$ quadrupole matrix

$\mathrm{M}_{-1} \quad-1$ order moment (K)

$N \quad$ acquisition points

Q flowrate $\left(\mathrm{m}^{3} \mathrm{~s}^{-1}\right)$

$R \quad$ resistance $\left(\mathrm{W}^{-1} \mathrm{~K}\right)$

$S \quad$ area $\left(\mathrm{m}^{2}\right)$

$T \quad$ temperature $(\mathrm{K})$

$X \quad$ sensitivity coefficient

a thermal diffusivity $\left(\mathrm{m}^{2} \mathrm{~s}^{-1}\right)$

$b \quad$ heater width $(\mathrm{m})$

e thickness (m)

$h \quad$ convective heat transfer coefficient $\left(\mathrm{W} \mathrm{m}^{-2} \mathrm{~K}^{-1}\right)$

$k \quad$ Fourier coefficient

$p \quad$ Laplace variable $\left(\mathrm{s}^{-1}\right)$

$r \quad$ radial coordinate $(\mathrm{m})$

$t \quad$ time $(\mathrm{s})$

$x \quad$ angular coordinate (rad) $z \quad$ axial coordinate $(\mathrm{m})$

Greek letters

$\alpha_{n} \quad$ Fourier variable

$\beta \quad$ parameters vector

$\phi \quad$ radial heat flux (W)

$\varphi \quad$ heat flux produced by the heater (W)

$\lambda$ thermal conductivity $\left(\mathrm{W} \mathrm{m}^{-1} \mathrm{~K}^{-1}\right)$

$\rho$ density $\left(\mathrm{kg} \mathrm{m}^{-3}\right)$

$\sigma^{2} \quad$ standard deviation

$\theta \quad$ Laplace transform of $T$

$\tau \quad$ characteristic time constant $\left(\mathrm{s}^{-1}\right)$

Symbols

- normalized

* $\quad$ Fourier transform

reduced

Subscripts

c clean

d deposit
A testing bench has been realised in which the probe is laid to obtain experimental results in clean or in fouling conditions.

At first, the probe description is realised. Then, the different transient forward models are developed and the theoretical sensitivity analysis from the 3D forward model is presented. Lastly, experimental data in clean and in fouling conditions are detailed and the estimation method is presented and validated.

\section{Probe description}

The studied probe, $50 \mathrm{~mm}$ length, $5 \mathrm{~mm}$ inside radius and $13 \mathrm{~mm}$ outside radius, can be described by a cylindrical multilayered system (Fig. 1). Each layer is $2 \mathrm{~mm}$ thick. The internal and the external layers are in stainless steel to be able to come under the same thermohydraulic and fouling influences as exchangers. A copper slab (10 $\mathrm{mm}$ length, $2 / 10 \mathrm{~mm}$ thick) heated by Joule effect produced by a heat step, encircling the centre section of the cylinder and is inserted between two other layers. These layers are in polytetrafluoroethylene polymer (PTFE) to be able to limit heat transfer from the heater and to make insignificant the contact resistances. The power supply to the heating element is controlled through a constant-voltage transformer. The final constituted pipe is inserted between two stainless steel tubes which act as heat exchangers parts. The temperature variation along the heater is measured by several $\mathrm{T}$ type thermocouples implanted parallel to the cylinder axis.

\section{Experimental device}

The probe is inserted into a testing bench named GAZPAR (GAZ PARticles) to be both tested in clean conditions and in fouling conditions. It is a three parts system (Fig. 2). The probe is mounted in a rectangular wind tunnel with $80 \times 80 \mathrm{~mm}^{2}$ a cross section. The fluid used is air at $323 \mathrm{~K}$. A flow of cool water is sent through the central stainless steel pipe to simulate real tubular heat exchangers conditions and to maintain the probe inlet surface temperature at a constant value.

The probe then acts as a foulant deposition site by simulating a heat exchanger tube in the gas stream. The primary constituents in exhaust gases causing fouling include $\mathrm{SiO}_{2}, \mathrm{Na}_{2} \mathrm{SO}_{4}$, and $\mathrm{CaSO}_{4}[16]$. So, fouling tests were carried out using sodium sulfate of $4 \mu \mathrm{m}$ medium diameter in the gas stream as foulant. The foulant particles are generated by ultrasound pulverization. Such generator achieves a particle size distribution close to monodispersion.

\section{Forward models}

The thermal quadrupole formalism using integral transforms methods [8] is used to model the three-dimensional transient heat transfer in the studied multilayered system. The interest of this approach lies in the fact that a linear relationship is given between the input and the output temperature and the heat flux after a double Laplace Fourier transform. The main advantage of this temperature-flux vector representation is to make the analytical modelling of multimaterials possible by multiplying the corresponding quadrupole matrices.

\subsection{D forward model}

The following case (Fig. 3) where the transient temperature measurement is achieved simultaneously and at the same location as a thermal excitation carried out by the heater is considered.

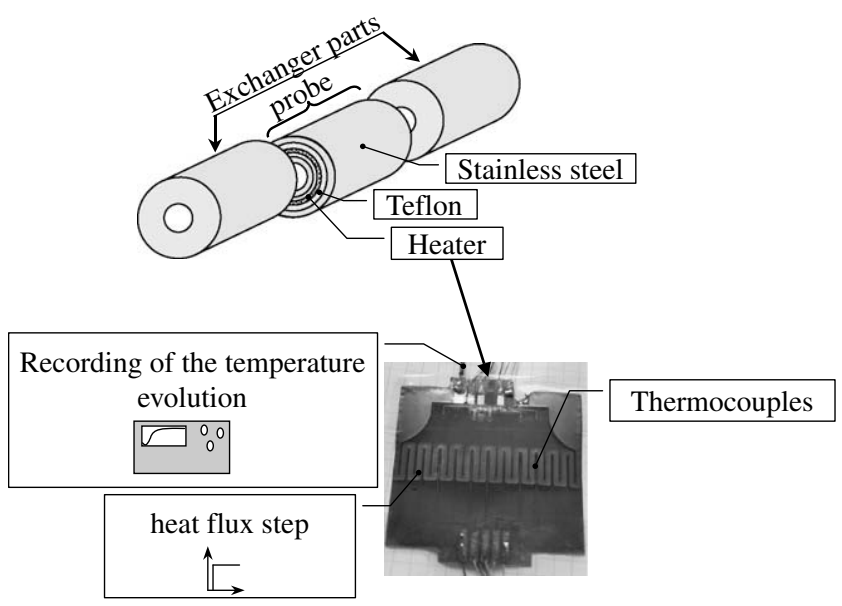

Fig. 1. Schematic diagram of heat transfer probe. 


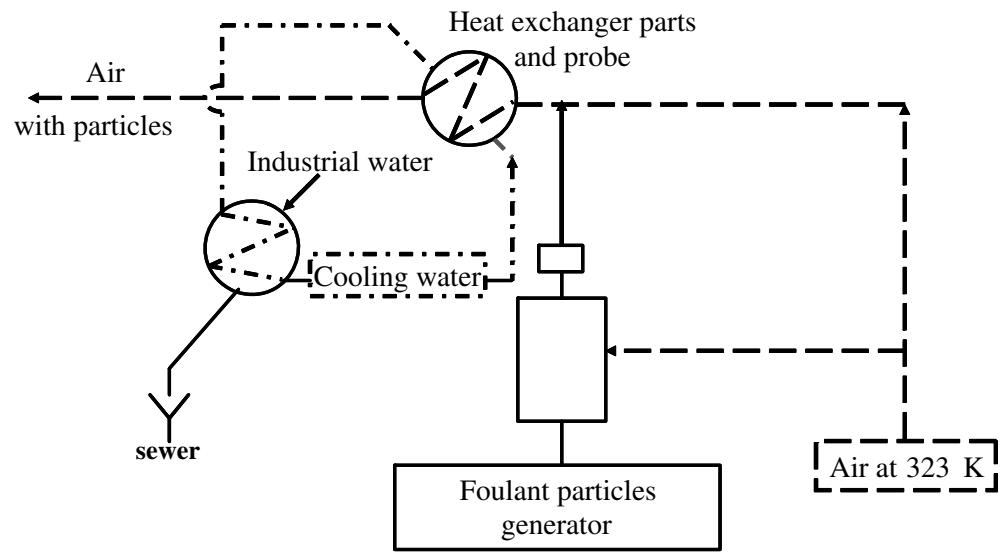

Fig. 2. Experimental device scheme GAZPAR.

In this model, the axial and radial and angular conductions into each layer and between the layers, the contact resistance between each layer and the probe inertia are considered. The three-dimensional transient heat transfer in the multilayered system supposes that the thermal properties are assumed to be constant during the experiment. The probe is initially at thermal equilibrium.

The temperature $T(r, z, x, t)$ at the level of the heater is the solution of the following heat equation in cylindrical coordinates:

$$
\begin{aligned}
& \frac{1}{r} \frac{\partial}{\partial r}\left(r \frac{\partial T(r, z, x, t)}{\partial r}\right)+\frac{1}{r^{2}} \frac{\partial^{2} T(r, z, x, t)}{\partial x^{2}}+\frac{\partial^{2} T(r, z, x, t)}{\partial z^{2}} \\
& \quad=\frac{1}{a} \frac{\partial T(r, z, x, t)}{\partial t}
\end{aligned}
$$

where $a$ is the thermal diffusivity, $r$ is the radial coordinate, $z$ is the axial coordinate and $x$ is the angular coordinate.

To solve the heat equation through an analytical way, it is convenient to consider the following boundary conditions of the problem:

$r=r_{7}-\lambda\left(2 \pi r_{7}\right) \frac{\partial T\left(r_{7}, z, x, t\right)}{\partial r}=h(r, x)\left(2 \pi r_{7}\right) T\left(r_{7}, z, x, t\right)$

$z=L \quad T(r, L, x, t)=0$

where $h(r, x)$ is the convective heat transfer coefficient.

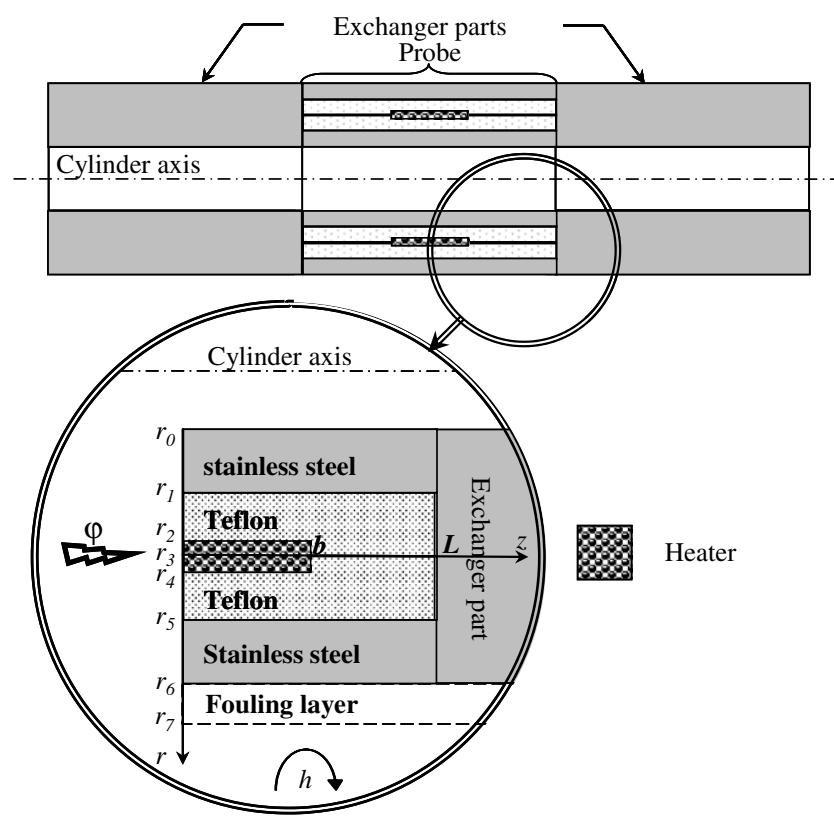

Fig. 3. Schematic representation of theoretical model.
Such condition (3) is a suitable approximation since the metallic sample in contact with the system at this boundary is very effusive. Such assumption has been verified with numerical simulation [22].

$r=r_{3}\left\{\begin{array}{l}\phi\left(r_{3}^{+}, z, x, t\right)=\phi\left(r_{3}^{-}, z, x, t\right)+\varphi H(t) \quad \text { if } \quad 0<z<b \\ \phi\left(r_{3}^{+}, z, x, t\right)=\phi\left(r_{3}^{-}, z, x, t\right) \quad \text { when } \quad 0<z<L\end{array}\right.$

where $H(t)$ is the Heaviside function and $\varphi$ is the heat flux produced in the heater.

The cooling water flowing through the inner cylinder sets its own temperature:

$r=r_{0} \quad T\left(r_{0}, z, x, t\right)=0$

The problem is considered as symmetric with respect to the plane $x=0$ and $z=0$. Indeed, the whirling frequency downstream the cylinder is up to $40 \mathrm{~Hz}$ in the considered operating conditions (air flow rate of $100 \mathrm{Nm}^{3} \mathrm{~h}^{-1}$ ). Thus, the wake effect can be neglected:

$\begin{array}{ll}z=0 & \frac{\partial T(r, 0, x, t)}{\partial z}=0 \\ x=0 & \frac{\partial T(r, z, 0, t)}{\partial x}=0 \\ x=\pi & \frac{\partial T(r, z, \pi, t)}{\partial x}=0\end{array}$

The initial condition is:

$t=0 \quad T(r, x, z, t=0)=0$

The periodicity conditions to the $x$-coordinate and the symmetry conditions relative to the $z$-coordinate enable to use the Fourier cosine transform of the temperature and of the flux in the $x$ - and $z$-direction associated with a Laplace transform applied to the time variable:

$$
\begin{aligned}
\tilde{\theta}\left(r, \alpha_{n}, k, p\right)= & \int_{0}^{\infty} \int_{0}^{L} \int_{0}^{\pi} T(r, z, x, t) \cos \left(\alpha_{n} z\right) \\
& \times \cos (k x) \mathrm{e}^{-p t} \mathrm{~d} x \mathrm{~d} z \mathrm{~d} t \quad \text { with } \\
& \alpha_{n}=\frac{\left(n+\frac{1}{2}\right) \pi}{L}
\end{aligned}
$$

where $\tilde{\theta}\left(r, \alpha_{n}, k, p\right)$ is the Laplace Fourier transform of the temperature $T(r, x, z, t)$.

Note that if the symmetry condition to the $x$-coordinate is not achieved, it would be more appropriate to consider complex Fourier transform to take into account the $x$-coordinate periodicity between $x=0$ and $x=2 \pi$.

So, the heat equation becomes in transformed space:

$\left.\frac{1}{r} \frac{\mathrm{d}}{\mathrm{d} r} r \frac{\mathrm{d} \tilde{\theta}\left(r, \alpha_{n}, k, p\right)}{\mathrm{d} r}\right)=\left(\frac{p}{a}+\alpha_{n}^{2}+\frac{k^{2}}{r^{2}}\right) \tilde{\theta}\left(r, \alpha_{n}, k, p\right)$ 
Eq. (11) admits for general solution:

$\tilde{\theta}\left(r, \alpha_{n}, k, p\right)=C_{1} I_{k}\left(\sqrt{\frac{p}{a}+\alpha_{n}^{2}} r\right)+C_{2} K_{k}\left(\sqrt{\frac{p}{a}+\alpha_{n}^{2}} r\right)$

where $C_{1}$ and $C_{2}$ are the integration constants and where $I_{k}$ and $K_{k}$ represent, respectively, the modified Bessel functions of the first kind and of the second kind.

The transformed expression of the boundary condition (4) yields:

$\tilde{\phi}\left(r_{3}^{+}, \alpha_{n}, k, p\right)=\tilde{\phi}\left(r_{3}^{-}, \alpha_{n}, k, p\right)+\frac{\varphi}{p} \frac{\sin \left(\alpha_{n} b\right)}{\alpha_{n}} \frac{\sin (k x)}{k}$

Expressions (11) and (13) are then equivalent to a quadrupole presentation. So, the following matrix relationship between the Laplace-Fourier temperature-flux vectors can be written using this quadrupole formalism for a cylindrical layer $r_{\text {out }}-r_{\text {in }}$ thick limited by two cylindrical surfaces of radii $r=r_{\text {in }}$ and $r=r_{\text {out }}$ :

$$
\begin{aligned}
& {\left[\begin{array}{c}
\tilde{\theta}\left(r, \alpha_{n}, k, p\right) \\
\tilde{\phi}\left(r, \alpha_{n}, k, p\right)
\end{array}\right]_{r_{\text {in }}}=M\left[\begin{array}{c}
\tilde{\theta}\left(r, \alpha_{n}, k, p\right) \\
\tilde{\phi}\left(r, \alpha_{n}, k, p\right)
\end{array}\right]_{r_{\text {out }}}} \\
& =\left[\begin{array}{cc}
A & B \\
C & D
\end{array}\right]_{r_{\text {in },}, r_{\text {out }}}\left[\begin{array}{c}
\tilde{\theta}\left(r, \alpha_{n}, k, p\right) \\
\tilde{\phi}\left(r, \alpha_{n}, k, p\right)
\end{array}\right]_{r_{\text {out }}}
\end{aligned}
$$

with the following values of the coefficients $A, B, C, D$ of the quadrupole matrix defined as:

$$
\left.\begin{array}{rl}
A & =\gamma r_{\text {out }}\left[I_{k}\left(\gamma r_{\text {in }}\right) K_{k+1}\left(\gamma r_{\text {out }}\right)+I_{k+1}\left(\gamma r_{\text {out }}\right) K_{k}\left(\gamma r_{\text {in }}\right)\right] \\
B & =\frac{1}{\pi \lambda}\left[I_{k}\left(\gamma r_{\text {out }}\right) K_{k}\left(\gamma r_{\text {in }}\right)-I_{k}\left(\gamma r_{\text {in }}\right) K_{k}\left(\gamma r_{\text {out }}\right)\right] \\
C & =\pi \lambda r_{\text {in }} r_{\text {out }} \gamma^{2}\left[I_{k+1}\left(\gamma r_{\text {out }}\right) K_{k+1}\left(\gamma r_{\text {in }}\right)-I_{k+1}\left(\gamma r_{\text {in }}\right) K_{k+1}\left(\gamma r_{\text {out }}\right)\right] \\
D & =\gamma r_{\text {in }}\left[I_{k}\left(\gamma r_{\text {out }}\right) K_{k+1}\left(\gamma r_{\text {in }}\right)+I_{k+1}\left(\gamma r_{\text {in }}\right) K_{k}\left(\gamma r_{\text {out }}\right)\right] \\
\text { with } \gamma & =\sqrt{\frac{p}{a}+\alpha_{n}^{2}}
\end{array}\right\}
$$

Each layer can now be described by its own quadrupole and the multilayered system can be modelled by multiplying the corresponding quadrupole matrix.

Finally, the temperature at the level of the heater in the Laplace-Fourier space can be written as:

$\tilde{\theta}\left(r_{3}, \alpha_{n}, k, p\right)=\left[\frac{C_{1}+D_{1} h\left(2 \pi r_{7}\right)}{A_{1}+B_{1} h\left(2 \pi r_{7}\right)}+\frac{A_{2}}{B_{2}}\right]^{-1} \frac{\varphi}{p} \frac{\sin \left(\alpha_{n} b\right)}{\alpha_{n}} \frac{\sin (k x)}{k}$

To return to the Laplace space, the appropriate inverse Fourier transform (17) is used:

$\theta\left(r_{3}, x, z, p\right)=\frac{2}{L} \sum_{n=0}^{N} \tilde{\theta}\left(r_{3}, \alpha_{n}, p\right) \cos \left(\alpha_{n} z\right)$

To return to the real time space, the Gaver-Stehfest numerical algorithm [15] is used.

At this stage, this model has too many approximations hard to check. Physical phenomena complexity (boundaries conditions validity, concept of heat transfer coefficient in transient state...) compared with industrial conditions (measurement noise...) does not allow to use the previous model to estimate accurately, in a classical manner, the heat transfer coefficient and the density variation of the fouling exposed layer. Nevertheless, a sensitivity study and the sizing probe are achieved thanks to this 3D forward model. However, a simplified 1D forward model was developed in clean and in fouling conditions by considering a homogeneous layer of fouling around the probe.

\subsection{Simplified 1D forward model in fouling conditions}

The electric equivalent representation of the problem is presented in Fig. 4:
This representation represents the physically simplified model and the different hypotheses made to simplify the model are the following one:

- The insulating layers are considered as only resistive $\left(R_{1}\right.$ and $\left.R_{2}\right)$.

- The metal layers are considered as only capacitive $\left(C_{\mathrm{s}}\right)$.

- The heater inertia is considered as negligible.

- The cooling water flowing through the inner cylinder sets its temperature.

- The contact resistances are considered as negligible.

- The heat transfer is considered as 1D according to the radial variable $r$.

- The deposit layer on the probe $\left(R_{\mathrm{d}}\right.$ and $\left.C_{\mathrm{d}}\right)$ is assumed to be homogeneous. Its average thermal conductivity is set at $0.07 \mathrm{~W} \mathrm{~m}^{-1} \mathrm{~K}^{-1}$ and its volumic heat at $3.5 \times 10^{5} \mathrm{~J} \mathrm{~m}^{-3} \mathrm{~K}^{-1}$.

Proceeding in the same way as previously, the temperature response at the level of the heater in real space can be written:

$$
\begin{gathered}
T\left(r_{3}, t, e_{\mathrm{d}}\right)=\underbrace{\frac{\varphi\left(R_{1} R_{2}\right)}{\left(R_{1}+R_{2}\right)}+\left[\frac{\varphi R_{2}^{2}\left(1+R_{\mathrm{d}} h 2 \pi r_{7}\right)}{\left[1+h 2 \pi r_{7}\left(R_{1}+R_{2}\right)\right]\left(R_{1}+R_{2}\right)}\right]}_{T_{\max }} \\
\cdot\left(1-e^{\left.-t / \tau_{\mathrm{d}}\right)}\right. \text { with } \\
\tau_{\mathrm{d}}=\frac{\left(R_{1}+R_{2}\right)\left(1+R_{\mathrm{d}} h 2 \pi r_{7}\right)\left(C_{\mathrm{d}}+C_{s}\right)}{\left[1+h 2 \pi r_{7}\left(R_{1}+R_{2}\right)\right]}=R_{\text {fouling }} C_{\text {fouling }}
\end{gathered}
$$

where $\tau_{\mathrm{d}}$ represents the characteristic time constant in fouling conditions. It can be defined by a product of a global resistance by a global capacity.

Such expression can be explained with reduced terms such as:

$T\left(r_{3}, t, e_{\mathrm{d}}\right)=T_{\max } f\left(\frac{t}{\tau}\right)$

Both simplified models are an excellent approximation of the 3D model. The heater inertia is more closely considered in the 3D model but there is no influence on the physical phenomena involved.

\section{Sensitivity analysis}

This probe design was subjected to technological constraints. Indeed, the internal and the external layers are in stainless steel to represent heat exchangers in industrial conditions at best. The sensitivity study enables to impose the various values of the missing parameters such as the thickness of the layers or the nature of the insulating material. This study allows the discussion on the possibility of physical parameters identification.

The reduced sensitivity functions of $T\left(r_{3}, x, z, t\right)$ to parameter $\eta_{i}$ will be defined by the following relation [21]:

$X_{\eta_{i}}^{*}(t)=\eta_{i} \frac{\partial T\left(r, x, z, t, \eta_{i}\right)}{\partial \eta_{i}}$

To characterise the fouling evolution around the probe, two parameters in the 3D forward model appear as essential:

- the air sight convective heat transfer coefficient $h$;

- the volumic heat variation of the fouling exposed layer due to fouling grow $\rho C_{p}$ which is equivalent to a thickness variation.

Indeed, the fouling involves a modification of these two transfer parameters. To size the probe in order to achieve the best compromise between industrial constraints and sensitivity analysis, it is useful to plot the reduced sensitivity functions of $T\left(r_{3}, \forall x, z, t\right)$ to these two parameters for several values (layer thickness, thermal conductivity, etc.) versus the duration of thermal excitation.

For example, the following two figures (Figs. 5 and 6) represent, respectively, the reduced sensitivity functions to $h$ and to $\rho C_{p}$ according to several values of the thermal conductivity of the 


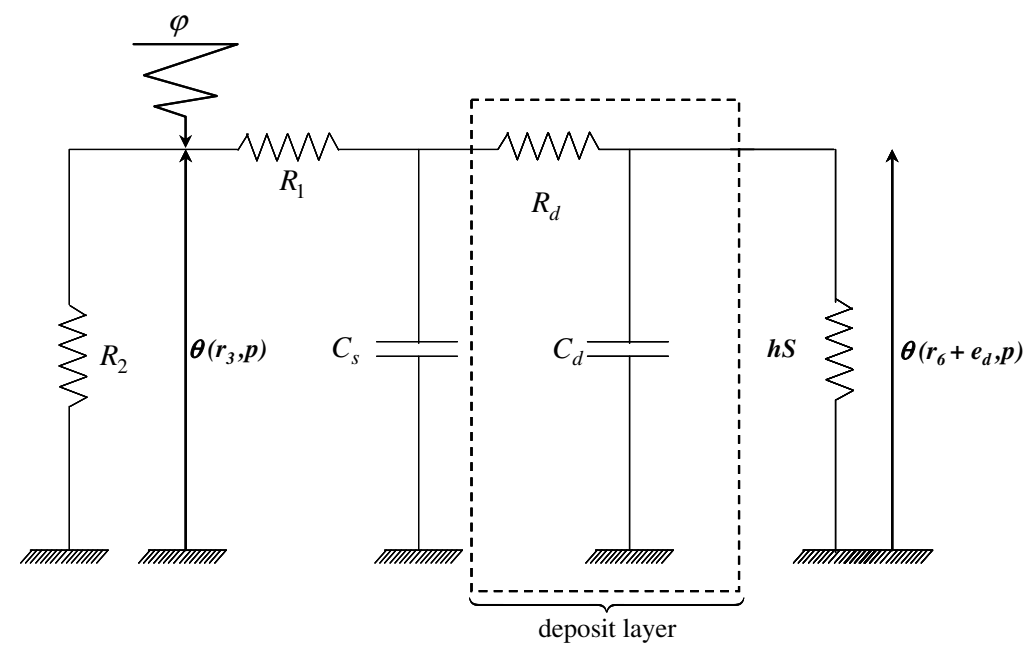

Fig. 4. Electric equivalent representation of the problem in fouling conditions.

closest air sight insulating layer varying from 0.25 to $40 \mathrm{~W} \mathrm{~m}^{-1} \mathrm{~K}^{-1}$ for a duration of thermal excitation of $1000 \mathrm{~s}$.

It is important to note that the higher this thermal conductivity, the more sensitive to $\rho C_{p}$ the temperature measured by the probe (Fig. 5) but it is less sensitive to $h$ (Fig. 6).

So, the available insulating material best answering the various constraints and the sensibilities is the PTFE. In the same way, the various thicknesses of layers were set at $2 \mathrm{~mm}$.

The physical properties of each layer and nominal values are given in Table 1.

Thus, the reduced sensitivity functions of $T\left(r_{3}, x, z, t\right)$ to $\rho C_{p}$, and to $h$ were calculated from the values of the chosen materials in Table 1 . They are plotted in Fig. 7.

This sensitivity study proves that the probe temperature signal is sensitive not only to the convective heat transfer coefficient $h$ but also to the volumic heat of the stainless steel layer subjected to fouling. However, the probe is sensitive to this volumic heat only for a period of time down to $300 \mathrm{~s}$ while it is sensitive to the convective heat transfer coefficient on the entire considered temporal domain.

\section{Experimental results}

To obtain experimental results both in clean conditions and in fouling conditions, the probe is inserted into the testing bench named GAZPAR.

\subsection{Experimental sensitivity study in fouling conditions}

Before carrying out fouling tests, it is necessary to wait for the thermohydraulical stabilisation of the experimental device GAZPAR. Once this stabilisation reached, foulant particles are produced by ultrasound pulverisation and they are injected into the hot wind tunnel. The tests were performed on a duration going from 13 to $72 \mathrm{~h}$, for an air flow rate of $100 \mathrm{Nm}^{3} \mathrm{~h}^{-1}$ with the air temperature set at $323 \mathrm{~K}$. So, the corresponding Reynolds number calculated from the probe diameter is $7.4 \times 10^{3}$. The particles dispersion air flow rate is set at $6.7 \times 10^{-8} \mathrm{~m}^{3} \mathrm{~s}^{-1}$.

Rather than using the 3D forward model, an experimental sensitivity study from the normalised experimental temperatures $\bar{T}\left(r_{3}, t, e_{\mathrm{d}}\right)$ was performed.

The normalised experimental temperature in fouling conditions $\bar{T}\left(r_{3}, t, e_{\mathrm{d}}\right)$ can be written:

$\bar{T}\left(r_{3}, t, e_{\mathrm{d}}\right)=\frac{T\left(r_{3}, t, e_{\mathrm{d}}\right)}{T_{\max }}$

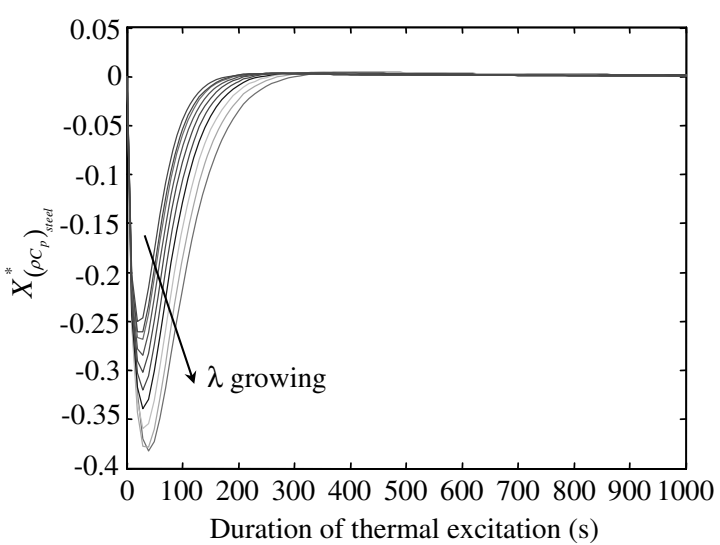

Fig. 5. Reduced sensitivity functions to $\rho C_{p}$ for different values of thermal conductivity.

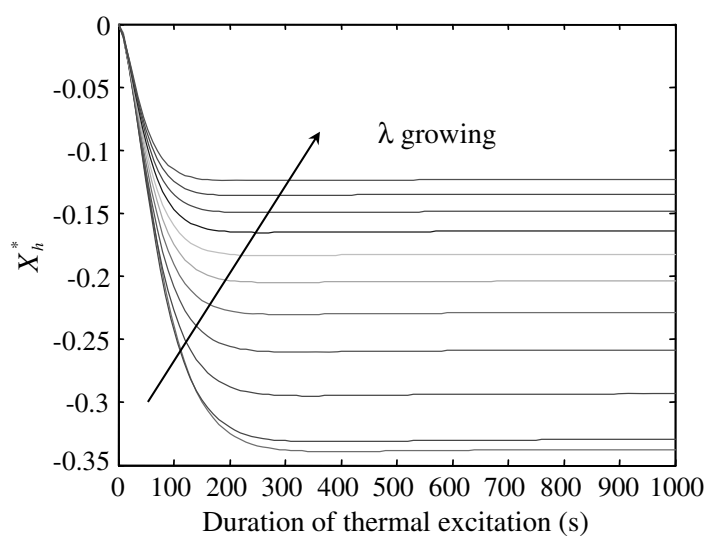

Fig. 6. Reduced sensitivity functions to $h$ for different values of thermal conductivity.

Fig. 8 represents a normalised experimental temperature $\bar{T}\left(r_{3}, t\right)$ in clean conditions and normalised experimental temperatures $\bar{T}\left(r_{3}, t, e_{\mathrm{d}}\right)$ after $72 \mathrm{~h}$ of fouling in the same thermohydraulic conditions.

Fig. 8 proves that the deposit formed on the probe only influences the probe characteristic time constant. Indeed, it is logical to assume that the variation of the characteristic time constant is only due to the thickness of the deposit on the probe because its response in temperature is not sensitive to the convective heat 
Table 1

Nominal values of the probe

\begin{tabular}{ll}
\hline Excitation heat flux & $\varphi=17,862 \mathrm{~W} \mathrm{~m}^{-2}$ \\
Stainless steel thermal conductivity & $\lambda_{\mathrm{s}}=16.3 \mathrm{~W} \mathrm{~m}^{-1} \mathrm{~K}^{-1}$ \\
Stainless steel specific heat & $\rho C_{\mathrm{ps}}=4 \times 10^{6} \mathrm{~J} \mathrm{~m}^{-3} \mathrm{~K}^{-1}$ \\
Stainless steel layer thickness & $e_{\mathrm{s}}=2 \times 10^{-3} \mathrm{~m}^{-1}$ \\
Teflon thermal conductivity & $\lambda_{\text {tef }}=0,25 \mathrm{~W} \mathrm{~m} \mathrm{~K}^{-1}$ \\
Teflon specific heat & $\rho C_{p \text { tef }}=2,2 \times 10^{6} \mathrm{~J} \mathrm{~m}^{-3} \mathrm{~K}^{-1}$ \\
Teflon layer thickness & $e_{\text {tef }}=2 \times 10^{-3} \mathrm{~m}$ \\
Heater thickness & $e_{\mathrm{h}}=0.2 \times 10^{-3} \mathrm{~m}$ \\
Heater width & $b=0.01 \mathrm{~m}$ \\
\hline
\end{tabular}

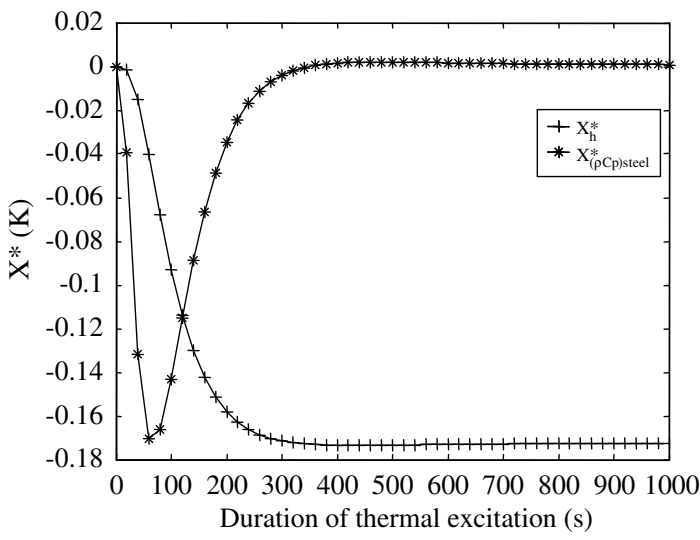

Fig. 7. Reduced sensitivity functions of $T\left(r_{3}, x, z, t\right)$ to $\rho C_{p}$, and to $h$.

transfer coefficient in transient state. Then, the fouling appears as a transient information. Consequently, it is possible to write the asymptotic first order development around the probe characteristic time constant. So, it comes:

$\bar{T}\left(r_{3}, t, e_{\mathrm{d}}\right)=\bar{T}\left(r_{3}, t\right)+\frac{\Delta \tau}{\tau_{\mathrm{c}}} t \frac{\partial \bar{T}\left(r_{3}, t\right)}{\partial t}$

This first order development is expressed generally under the following way:

$\bar{T}\left(r_{3}, t, e_{\mathrm{d}}\right)=\bar{T}\left(r_{3}, t\right)+\Delta \tau \frac{\partial \bar{T}\left(r_{3}, t\right)}{\partial \tau}$

However, the major drawback of this expression computation lies in the fact that it is necessary to know accurately the nominal values of the problem.

Thus, the experimental sensitivity coefficient in fouling conditions is:

$X\left(r_{3}, t, e_{\mathrm{d}}\right)=\bar{T}\left(r_{3}, t, e_{\mathrm{d}}\right)-\bar{T}\left(r_{3}, t\right)=\frac{\Delta \tau}{\tau_{\mathrm{c}}} t \frac{\partial\left(\bar{T}\left(r_{3}, t\right)\right)}{\partial t}$

The different experimental sensitivity coefficients to the fouling for various duration of fouling are plotted in Fig. 9.

These different experimental sensitivity coefficients to the fouling are calculated from all the signal data and not from the nominal values of the problem. One can note the similarity of curves shapes between the experimental and the theoretical sensitivity analysis to fouling (Fig. 10).

\subsection{Method of estimation and results in fouling conditions}

It is then possible to write the corresponding order -1 moment by integrating the relation (24) as:

$$
\begin{aligned}
\mathrm{M}_{-1} & =\int_{t=0}^{t=t_{\max }} \frac{1}{t}\left(\bar{T}\left(r_{3}, t, e_{\mathrm{d}}\right)-\bar{T}\left(r_{3}, t\right)\right) \mathrm{d} t \\
& \left.=\int_{t=0}^{t=t_{\max }} \frac{\Delta \tau}{\tau_{\mathrm{c}}} \frac{\partial \bar{T}\left(r_{3}, t\right)}{\partial t}\right) \mathrm{d} t
\end{aligned}
$$

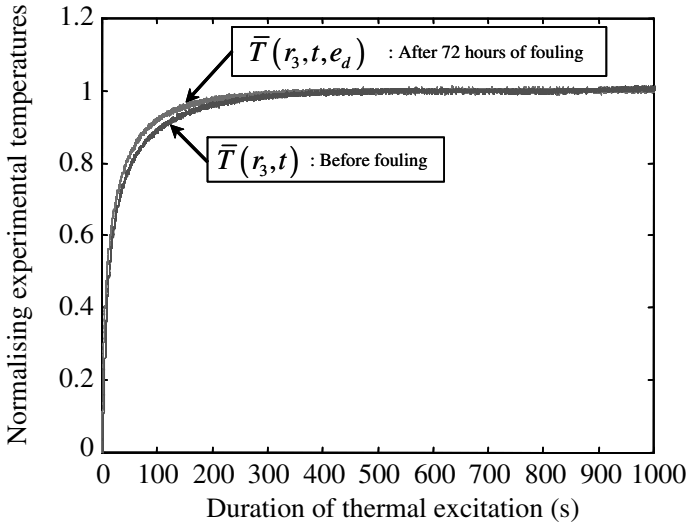

Fig. 8. Normalized experimental temperatures in clean conditions and after $72 \mathrm{~h}$ of fouling.

or:

$\mathrm{M}_{-1}=\int_{t=0}^{t=t_{\max }}\left(\frac{X\left(r_{3}, t, e_{\mathrm{d}}\right)}{t}\right) \mathrm{d} t$

Thus:

$\mathrm{M}_{-1}=\int_{t=0}^{t=t_{\max }}\left(\frac{X\left(r_{3}, t, e_{\mathrm{d}}\right)}{t}\right) \mathrm{d} t=\frac{\Delta \tau}{\tau_{\mathrm{c}}}$

So, each -1 order moment can be directly calculated from the experimental sensitivity coefficients for each duration of fouling by a simple integration.

Thanks to the 1D simplified models in clean conditions and in fouling conditions, the probe characteristic time constants $\tau_{\mathrm{c}}$ and $\tau_{\mathrm{d}}$ can be written as:

$\tau_{\mathrm{c}}=R \cdot C \quad$ and $\quad \tau_{\mathrm{d}}=R_{\text {fouling }} \cdot C_{\text {fouling }}$

where $R_{\text {fouling }}$ and $C_{\text {fouling }}$ are dependent on the fouling thickness.

Thus, a variation of the deposit thickness on the probe entails a variation of $R_{\text {fouling }}$ and of $C_{\text {fouling. }}$ It becomes possible to write:

$\tau_{\mathrm{d}}=\tau_{\mathrm{c}}+\Delta \tau=\left(R+\frac{\Delta e_{\mathrm{d}}}{\lambda_{\mathrm{d}}}\right) \cdot\left(C+\left(\rho C_{p}\right)_{\mathrm{d}} \Delta e_{\mathrm{d}}\right)$

where $\lambda_{\mathrm{d}}$ is the thermal conductivity of the deposit and $\left(\rho C_{p}\right)_{\mathrm{d}}$ is its density. So, it comes:

$$
\begin{aligned}
\frac{\Delta \tau}{\tau_{\mathrm{c}}} & \left.\left.=\frac{\left(\rho C_{p}\right)_{\mathrm{d}}}{\lambda_{\mathrm{d}} R C}\right)\left(\Delta e_{\mathrm{d}}\right)^{2}+\frac{\left(\rho C_{p}\right)_{\mathrm{d}}}{R}+\frac{1}{\lambda_{\mathrm{d}} C}\right) \Delta e_{\mathrm{d}} \\
& =\beta_{1}\left(\Delta e_{\mathrm{d}}\right)^{2}+\beta_{2} \Delta e_{\mathrm{d}}
\end{aligned}
$$

The -1 order moment obtained from the various experimental sensitivity coefficients is thus proportional to deposit thickness:

$\mathrm{M}_{-1}=\beta_{1}\left(\Delta e_{\mathrm{d}}\right)^{2}+\beta_{2} \Delta e_{\mathrm{d}}$

where $\Delta e_{\mathrm{d}}=\left(e_{\mathrm{d}}\right)_{t=t_{\mathrm{i}}}-\left(e_{\mathrm{d}}\right)_{t=0}$. The term $\left(\Delta e_{\mathrm{d}}\right)^{2}$ is a two-order term, it could be considered as negligible. First, it is necessary to estimate the coefficients $\beta_{1}$ and $\beta_{2}$. The problem of estimation can be written as:

$$
\underbrace{\left[\begin{array}{c}
\left(\mathrm{M}_{-1}\right)_{t_{\mathrm{d}}=0} \\
\vdots \\
\left(\mathrm{M}_{-1}\right)_{t_{\mathrm{d}}=t_{i}}
\end{array}\right]}_{\left[\mathrm{M}_{-1}\right]}=\underbrace{\left[\begin{array}{cc}
\left(\Delta e_{\mathrm{d}}\right)_{t=0}^{2} & \left(\Delta e_{\mathrm{d}}\right)_{t=0} \\
\vdots & \vdots \\
\left(\Delta e_{\mathrm{d}}\right)_{t=t_{i}}^{2} & \left(\Delta e_{\mathrm{d}}\right)_{t=t_{i}}
\end{array}\right]}_{[\mathrm{X}]} \underbrace{\left[\begin{array}{c}
\beta_{1} \\
\beta_{2}
\end{array}\right]}_{[\beta]}
$$

If the noise is correlated or not a constant deviation during time, the Gauss-Markov method can be used as:

$[\beta]=\left[[X]^{t} \operatorname{cov}\left(e_{\mathrm{M}_{-1}}\right)^{-1}[X]\right]^{-1}[X]^{t} \operatorname{cov}\left(e_{\mathrm{M}_{-1}}\right)^{-1}\left[\mathrm{M}_{-1}\right]$ 

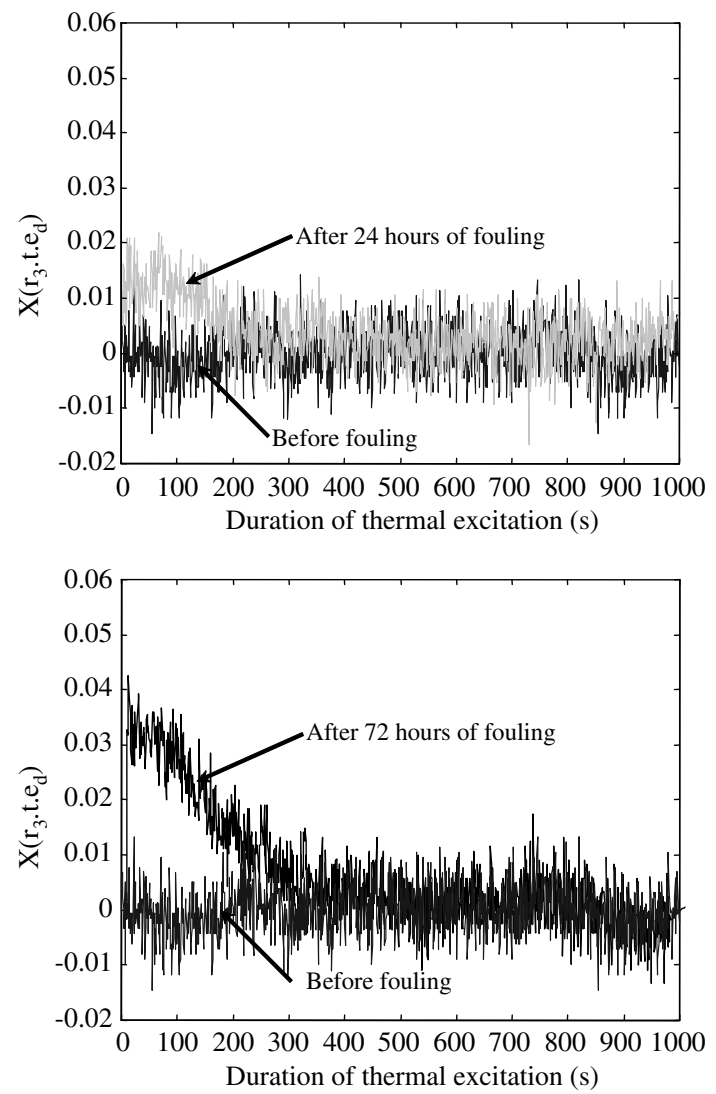

Fig. 9. Experimental sensitivity coefficients to fouling for various duration of fouling.

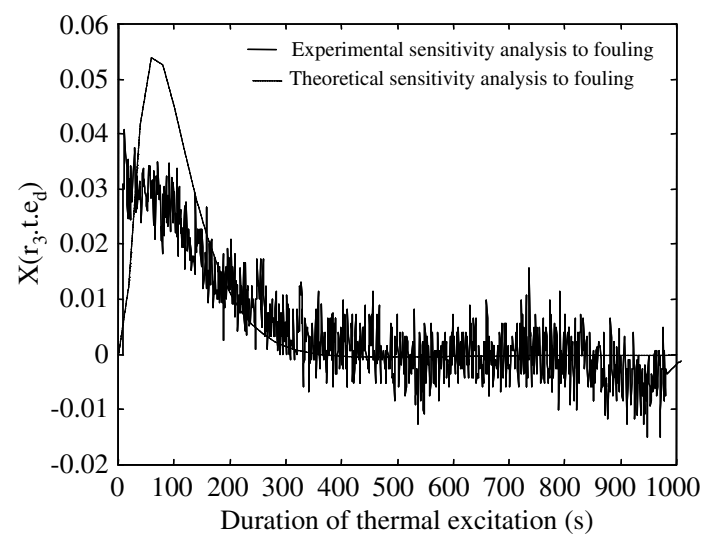

Fig. 10. Comparison between experimental and theoretical sensitivity coefficients to fouling.

where $\operatorname{cov}\left(e_{\mathrm{M}_{-1}}\right)$ represents the covariance matrix of the noise measurement.

The interest of this estimation lies in the fact that it is not greatly dependent on the considered forward model and on the nominal values of the problem. Indeed, the experimental sensitivity coefficients are calculated from the signal and not from the nominal values of the considered forward model.

Once the tests in fouling conditions were completed, the deposit pattern around the probe for each considered duration of fouling is measured by a laser profiler. These are plotted in Fig. 11. For the considered fouling conditions, various deposit regimes such as the inertial impaction and the turbulent diffusion occur. This comment explains why the measured deposit pattern is not homogeneous around the probe. Every average deposit thickness is calculated by integrating these values by the trapeze method.

Because of the limited volume of the sulphate sodium solution tank supplied the particles generator, the fouling tests were performed within a maximal duration of $72 \mathrm{~h}$. So, it is difficult to estimate accurately the parameters $\beta_{1}$ and $\beta_{2}$. However, as the -1 order moments are independent on the considered forward model and on the associated nominal values, it becomes possible to calculate $\beta_{1}$ and $\beta_{2}$ from the sensitivity coefficients obtained from the 1D simplified models.

These two simplified forward model responses have been numerically noise-added before calculating the theoretical -1 order moment which has allowed obtaining the corresponding standard deviation.

So, Fig. 12 represents the experimental and theoretical -1 order moments and their associated standard deviation. The -1 order moments obtained from the 3D forward model are also plotted in this figure.

This figure shows that the -1 order moments are no dependent on the considered forward model and on the nominal values of the problem. Besides, it shows that the noise is not correlated and that the -1 order moments are obtained accurately. So, from the -1 order moment values and from Eq. (33), it is possible to estimate the parameters $\beta_{1}$ and $\beta_{2}$. From these parameter values and from the knowledge of the experimental -1 order moment for a duration of fouling, the deposit thickness around the probe can be calculated such as:

$\Delta e_{\mathrm{d}}=e_{\mathrm{d}}=\frac{-\beta_{2}+\sqrt{\Delta}}{2 \beta_{1}} \quad$ with $\quad \Delta=\left(\beta_{2}\right)^{2}+4 \beta_{1} \mathrm{M}_{-1}$

Afterward, from the knowledge of the convective heat transfer coefficient in clean conditions, from the knowledge of the average deposit thicknesses around the probe, the conductance in fouling conditions can be calculated by:

$\left(\frac{1}{h}\right)_{\mathrm{d}}=\left(\frac{1}{h}\right)_{\mathrm{c}}+\frac{e_{\mathrm{d}}}{\lambda_{\mathrm{d}}}$

where $\lambda_{\mathrm{d}}=0.07 \mathrm{~W} \mathrm{~m}^{-1} \mathrm{~K}^{-1}$.

\section{Conclusions}

A transient thermal fouling probe was designed to replace one part or the totality of heat exchanger tubes. This probe becomes representative of the thermohydraulical and fouling conditions as heat exchangers whereas classical methods tend to characterise the phenomenon involved too late for relevant use.

The principle of the method is linked to the processing of transient temperature elevations carried out by a heater inside the tube wall.

An experimental sensitivity study was implemented in order to estimate not only the average heat transfer coefficient but also the average fouling thickness around the tube. The sensitivity coefficients are obtained from the temporal variation of the experimental temperatures and not from the nominal values of the forward model as they usually are.

The validation of the device was performed in a calibrated environment and the fouling thickness was verified with optical measurements.

This probe has shown its capacity to allow the determination of the convective heat transfer coefficient in clean conditions and the determination of the deposit thickness around the heat exchanger in fouling conditions from a new method of estimation. 


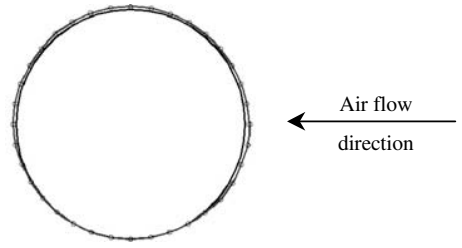

Deposit pattern after 13 hours of fouling

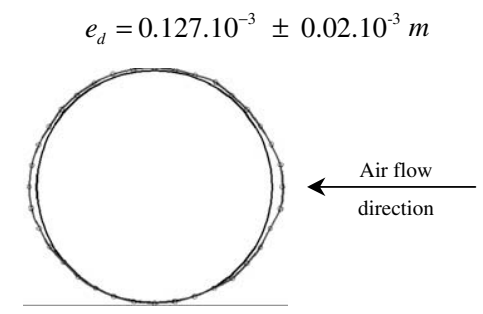

Deposit pattern after 48 hours of fouling

$$
e_{d}=0.341 .10^{-3} \pm 0.02 .10^{-3} \mathrm{~m}
$$

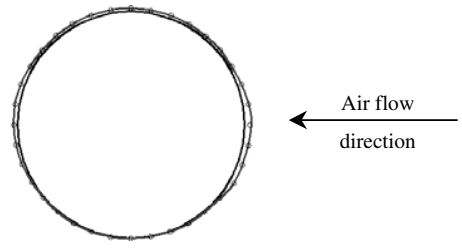

Deposit pattern after 24 hours of fouling

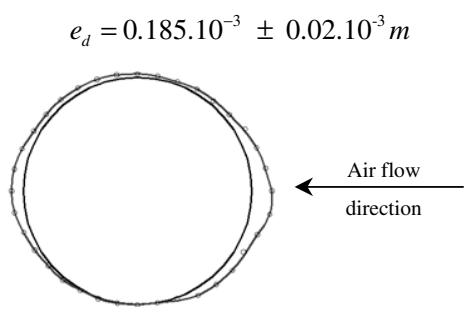

Deposit pattern after 72 hours of fouling

$$
e_{d}=0.697 .10^{-3} \pm 0.02 .10^{-3} \mathrm{~m}
$$

Fig. 11. Deposit pattern for different duration of fouling.

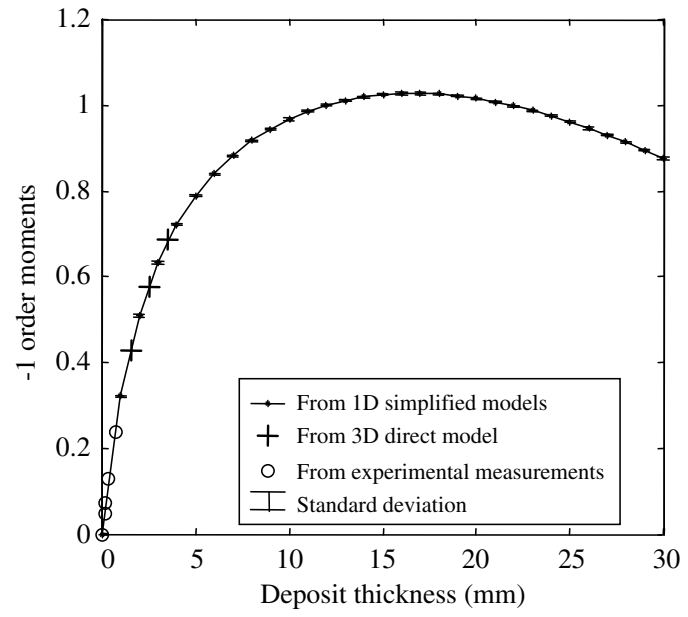

Fig. 12. Various -1 order moments versus deposit thickness.

The results were successfully confronted with the data available from the literature and with the experimental measurements obtained optically.

The advantages of such a device are to be cheap, localised and technologically simple associated with adapted data processing. The transient state estimation method developed is robust. It is not greatly dependent on noise measurement and on the nominal values of the problem.

The perspectives of this work are to extend the method to other exchanger technologies (liquid-liquid, plate heat exchangers, etc.) and other fouling conditions (corrosion, scaling, etc.).

\section{References}

[1] S.K. Beal, Deposition of particles in turbulent flow on channel or pipe walls, Nuclear Science and Engineering (1970).

[2] D. Bouris, G. Bergeles, Particle-surface interactions in heat exchanger fouling Journal of Fluids Engineering 118 (1996) 574-581.

[3] N. Epstein, Fouling in heat exchangers, in: Heat Transfer 1978: Sixth International Heat Transfer Conference, 1978, pp. 235-253.
[4] N.F. Glen, J.H. Howarth, Modelling refuse incineration fouling, in: Second United Kingdom Conference on Heat Transfer, Institute of Mechanical Engineering, vol. 1, 1988, pp. 401-420.

[5] J.D. Isdale, A.C. Scott, G. Cartwright, The use of probes to assess fouling in dirty gas streams, in installation effects in ducted fan systems, Institution of Mechanical Engineers, Londres (1984) 10-118.

[6] D.Q. Kern, R.E. Seaton, A theoretical analysis of thermal surface fouling, Britanic Chemical Sciences 4 (5) (1959) 258-262.

[7] H.H. Krause, P.W. Cover, W.E. Berry, R.A. Olexsey, Corrosion and deposit from combustion of solid waste. Part VII: coincineration of refuse and sewage sludge, Journal Engineering for Power 102 (1980) 698-705.

[8] D. Maillet, S. André, J.C. Batsale, A. Degiovanni, C. Moyne, Thermal Quadrupoles, Solving the Heat Equation Through Integral Transforms, Wiley, New York, 2000.

[9] W.J. Marner, Progress in gas-side fouling of heat transfer surfaces, Applied Mechanical Revue 43 (1990) 35-66.

[10] J. Marner, K.S. MacDavid, L.J. Muzio, Development of a gas side measuring device, in: Heat Transfer Fundamentals Design, Applications and Operating Problems, R.K. Shaw Editions, vol. 108, 1987, pp. 305-314.

[11] A.L. Plumley, W.R. Roczniak, Natural occurring high-chloride coal and superheater corrosion, Journal Engineering for Power 104 (1982) 874-884.

[12] D.E. Rosner, R.M. Atkins, Experimental Studies of Salt/ash Deposition Rates From Combustion Products Using Optical Techniques, in Fouling and Slagging Resulting From Impurities in Combustion Gases, R.W. Bryers Edition, New York, 1983.

[13] A.K. Seikh, S.M. Zubair, M. Younas, M.O. Budair, A risk based heat exchanger analysis subject to fouling. Part II: economics of heat exchangers cleaning, 2000 Elsevier Science, 2000, pp. 445-461.

[14] M. Sohal, S. Field, Testing of a probe to measure fouling in an industrial flue gas stream, Heat Transfer Engineering 14 (2) (1993).

[15] H. Stehfest, Remark on algorithm 368, numerical inversion of Laplace transform, ACM 53 (10) (1970) 624.

[16] J. Taborek, T. Aoki, R.B. Ritter, J.W. Palen, Fouling: the major unresolved problem in heat transfer, Chemical Engineering Process 68 (2) (1979) 59-67.

[17] A.K. Temu, E. Naess, O.K. Sonju, Development and testing of a probe to monitor gas side fouling in cross flow, Heat Transfer Engineering 23 (2002).

[18] D. Thomas, U. Grigull, Experimental Investigation of the Deposition of Suspended Magnetite From the Fluid Flow in Steam Generating Boiler Tubes, Brennst-Warme Kraft, 1974. pp. 109-115.

[19] A.P. Watkinson, N. Epstein, Particulate fouling of sensible heat exchangers, in: Fourth International Heat Transfer Conference, vol. 1, 1970, pp. 1-12.

[20] L. Perez, B. Ladevie, P. Tochon, J.C. Batsale, A convenient probe for the 2D thermal detection of fouling of tubular heat exchangers, International Journal of Heat Exchangers VII 2 (2006).

[21] J.V. Beck, K.J. Arnold, Parameter Estimation in Engineering and Science, Wiley, New York, 1977.

[22] L. Perez, Développement, étude de performances et intégration de sondes thermiques pour la caractérisation de l'encrassement d'échangeurs tubulaires à courants croisés, Ph.D. Thesis, 2003. Available from: http:// pastel.paristech.org/984/. 